\title{
O SUPREMO TRIBUNAL FEDERAL E A CONFIGURAÇÃO DA NECESSIDADE DO INDIVÍDUO: UMA ANÁLISE DO CRITÉRIO DE MISERABILIDADE NA LEI ORGÂNICA DA ASSISTÊNCIA SOCIAL
}

\author{
THE FEDERAL SUPREME COURT AND THE CONFIGURATION OF THE \\ NECESSITY OF THE INDIVIDUAL: AN ANALYSIS OF THE MISERABILITY \\ CRITERIA IN THE ORGANIC LAW OF SOCIAL ASSISTANCE
}

\author{
${ }^{1}$ Fábio Rezende Braga \\ ${ }^{2}$ Elisa Schmidlin Cruz
}

\section{RESUMO}

No Brasil, o Benefício Assistencial de Prestação Continuada (BPC) é concedido mensalmente a idosos e deficiente físicos em situação de risco social e carência econômica. Em que pese a expressa previsão constitucional que determina o amplo acesso ao referido benefício, a Lei Orgânica da Assistência Social (LOAS) estabelece, dentre outros, critério objetivo de miserabilidade que restringe a abrangência do direito à percepção do BPC. A matéria, por sua relevância, foi julgada pelo Supremo Tribunal Federal (STF) em mais de uma oportunidade. Pelo exposto, intenciona o presente artigo demonstrar os diferentes posicionamentos já sustentados pelo STF no enfrentamento da problemática envolvendo o critério de miserabilidade positivado na LOAS e, por fim, evidenciar o atual entendimento da Suprema Corte brasileira sobre a configuração da situação de necessidade do indivíduo. O trabalho tem caráter qualitativo e a construção dos dados é realizada sobre a base da legislação vigente, complementada por pesquisa bibliográfica e jurisprudencial, que oferecem o aporte necessário para compreender os conceitos e princípios que estruturam o objeto perquirido.

Palavras-chave: Supremo tribunal federal (stf), Necessidade, Miserabilidade, Lei orgânica da assistência social (loas)

\footnotetext{
${ }^{1}$ Mestrando em Direito da Pontifícia Universidade Católica do Paraná - PUC/PR, Paraná (Brasil). E-mail: frezendebraga@gmail.com

${ }^{2}$ Mestranda em Direito da Pontifícia Universidade Católica do Paraná - PUC/PR, Paraná (Brasil). E-mail: elisa.cruz@acp.org.br
} 


\begin{abstract}
In Brazil the Continuous Cash Benefit Program (BPC) is granted monthly to elderly and physically disabled citizens in the situation of social risk an economic necessity. Despite the express constitutional provision that determines broad access to the benefit, the Organic Law of Social Assistance (LOAS) provisions, among others, an objective criteria of miserability that restrains the coverage of the BPC. The subject, due to its relevance, was submitted to the Brazilian Federal Supreme Court (STF) in more than one opportunity. Given the above said, the present article intends to demonstrate the different positions already sustained by the STF when addressing the matter of the miserability criteria mentioned at LOAS, as well as to determine the current understanding of the Court regarding the configuration of the necessity of the individual. This work is a qualitative review and the gathering of data consisted of analyses of the current legislation, complemented by bibliographical and jurisprudential research, all of which offer the necessary support in order to understand the concepts and principles that compose the object under study.
\end{abstract}

Keywords: Federal supreme court (stf), Necessity, Miserability, Organic law of social assistance (loas) 


\section{INTRODUÇÃO}

O público alvo das ações de caráter assistencial são aqueles indivíduos hipossuficientes, que vivem em constante risco social. Seguindo essa lógica, a Constituição de 1988, em consonância com o princípio da dignidade da pessoa humana e com os objetivos regentes da República Federativa do Brasil de erradicação da pobreza e marginalização e redução das desigualdades sociais, incluiu o instituto da Assistência Social como sendo um instrumento da Seguridade Social. Garantiu-se, assim, o direito fundamental de proteção e assistência aos desamparados.

Em atenção ao dever de assistencialismo constitucionalmente positivado, dispõe o referido diploma legal que a Assistência Social será devida a quem dela necessitar e, dentre suas garantias, nos termos do artigo 203, inciso V, da Constituição da República, está a previsão de prestação mensal - no valor de um salário mínimo vigente - ao deficiente e ao idoso que lograr êxito em comprovar impossibilidade de prover a própria subsistência e, de igual forma, tê-la provida por seu grupo familiar. Assim, o Benefício de Prestação Continuada de Assistência Social (BPC) está ligado à satisfação das necessidades vitais que condicionam a existência da parcela mais carente e desamparada da população brasileira: idosos e pessoas com deficiência.

Com o advento da Lei Orgânica da Assistência Social (LOAS), editada com a finalidade de regulamentar o preceito constitucional acima referido, dentre todos os requisitos indispensáveis à concessão do BPC restou estabelecido um critério objetivo para aferir o grau de miserabilidade exigido: determinou-se, no $\S 3^{\circ}$ do artigo 20 da LOAS, que para fins de configuração da necessidade do indivíduo a renda familiar per capita teria de ser inferior a $1 / 4$ (um quarto) do salário mínimo vigente. Por consequência, aqueles que superavam o limite imposto por lei, mas que ainda assim encontravam-se em situação de necessidade e incapacitados para trabalhar, estavam completamente desprotegidos no sistema de Seguridade Social.

Ocorre que a impossibilidade de receber cobertura previdenciária - decorrente da ausência de condições financeiras mínimas para efetuar contribuições - e também de gozar de proteção assistencial - por não atender os critérios legais - afronta diretamente os objetivos gerais do Sistema de Seguridade Social brasileiro, especialmente ao obstar a universalidade da cobertura de atendimento e a ampla garantia de prestação da Assistência Social, avalizadas no artigo 203, caput, da Constituição da República. 
Dentro desse contexto, o Supremo Tribunal Federal (STF) julgou a questão em mais de uma oportunidade e, não obstante tenha anteriormente reconhecido a constitucionalidade do $\S 3^{\circ}$ do artigo 20 da LOAS, revisitou recentemente seu posicionamento e declarou inconstitucional o critério econômico objetivo até então previsto como limitador à concessão do benefício assistencial.

Em seu voto, pronunciando a inconstitucionalidade do referido dispositivo legal, o ministro relator Gilmar Mendes considerou o parâmetro econômico defasado para qualificar a situação de miserabilidade e defendeu a necessidade de exercício imediato de novo juízo pelo STF em virtude do câmbio substancial da realidade fática, política, socioeconômica e jurídica da norma infraconstitucional desde sua edição - em 1993 - e de seu anterior julgamento pela Suprema Corte, há mais de uma década.

Pelo exposto, intenciona o presente artigo demonstrar - sem pretensão de exaurir a matéria - os diferentes posicionamentos já sustentados pelo STF no enfrentamento da problemática envolvendo o critério de miserabilidade positivado na LOAS e, por fim, evidenciar o atual entendimento da Suprema Corte brasileira sobre a configuração da situação de necessidade do indivíduo. $\mathrm{O}$ trabalho tem caráter qualitativo e a construção dos dados será realizada sobre a base da legislação vigente, complementada por pesquisa bibliográfica e jurisprudencial, que oferecerão o aporte necessário para compreender os conceitos e princípios que estruturam o objeto perquirido.

Para tanto, o estudo foi estruturado em três etapas, que bem demonstram os pontos focais ora analisados: a primeira destina-se a apresentar ao leitor uma síntese da previsão constitucional do benefício de prestação continuada e da regulamentação dos requisitos exigidos para sua concessão conforme o disposto na Lei Orgânica da Assistência Social; a segunda, enfoca especificamente do critério objetivo de miserabilidade previsto na LOAS e traça um comparativo entre a realidade socioeconômica dos beneficiários e a legislação brasileira; por fim, a terceira resume os posicionamentos até hoje adotados pelo Supremo Tribunal Federal, revelando a atual concepção dada pelo STF à caracterização da situação de necessidade do indivíduo.

1 PREVISÃO CONSTITUCIONAL DO BENEFÍCIO DE PRESTAÇÃO CONTINUADA E REGULAMENTAÇÃO DOS CRITÉRIOS NA LEI ORGÂNICA DA ASSISTÊNCIA SOCIAL

Em atenção ao dever de assistência no Estado Social de Direito Brasileiro, o artigo 
203 da Constituição da República estabelece - com base no princípio da solidariedade - o alcance e importância conferidos à Assistência Social quando determina que a mesma será prestada a qualquer cidadão que dela necessitar. ${ }^{1}$ Seus beneficiários, portanto, não ficam limitados à obrigatoriedade de filiação, contribuição, ou desempenho de atividade laboral. A condição de carência econômica é o único critério exigível, em um primeiro momento, à concessão de benefícios dessa natureza.

Conforme anteriormente exposto, o benefício de prestação continuada encontra-se inserido no contexto da Assistência Social que, por sua vez, é uma vertente do Sistema de Seguridade Social brasileiro. Assim, por disposição constitucional, referido benefício deve ser entendido como um direito social fundamental. ${ }^{2}$

O BPC encontra fundamento constitucional expresso no inciso V do artigo 203 da Constituição de 1988 e, por determinação legal, representa a garantia de um salário mínimo nacional, concedido mensalmente à pessoa com deficiência ou idosa que não tenha condições de prover sua própria subsistência e, de igual forma, tê-la provida por seu grupo familiar, em consonância com o que dispuser a lei.

Consoante entendimento doutrinário corroborado por decisão do Supremo Tribunal Federal, claro está que a norma inserida no artigo 203, inciso V da Constituição é de eficácia limitada e, portanto, depende de regulamentação - por meio da legislação ordinária - para fixar os critérios aplicáveis no momento da concessão do benefício assistencial. ${ }^{3}$

Assim, visando atender a necessidade de normatização dos parâmetros constitucionalmente impostos, foi editada, em 07 de dezembro de 1993, a Lei Orgânica da Assistência Social (Lei $n^{\circ}$ 8.742/93). Inicialmente regulamentada pelo Decreto $n^{0} 1.744 / 95$, que por sua vez foi alterado pelo Decreto $n^{\circ} 4.712 / 2003$, ambos revogados pelo Decreto $n^{\circ}$

1 A Política Nacional de Assistência Social, aprovada pelo CNAS, em 1998, tem por destinatários as pessoas pertencentes aos segmentos involuntariamente excluídos de políticas sociais básicas, priorizando indivíduos que se encontrem em: "a) condições de vulnerabilidade próprias do ciclo de vida, que ocorrem predominantemente em crianças de zero a cinco anos e em idosos acima de sessenta anos; b) condições de desvantagem pessoal resultante de deficiência ou de incapacidades, que limitam ou impedem o indivíduo no desempenho de uma atividade considerada normal para a sua idade e sexo, face ao contexto sócio-cultural no qual se insere; c) situações circunstanciais e conjunturais como abuso e exploração comercial sexual infanto-juvenil, trabalho infanto-juvenil, moradores de rua, migrantes, dependentes do uso e vítimas de exploração comercial de drogas, crianças e adolescentes vítimas de abandono e desagregação familiar, crianças, idosos e mulheres vítimas de maus tratos". (MUNIZ, 2005, p. 292).

2 Oportuno lembrar que cabe ao Estado garantir a prestação dos direitos sociais, o que acaba por gerar um problema de eficácia já que, mesmo reconhecidos constitucionalmente, tais direitos encontram obstáculos políticos e econômicos no momento de sua concessão. Ainda por este motivo, a efetivação do BPC está diretamente ligada à eficácia de políticas públicas de distribuição de renda que tenham por objetivo a çoncretização da dignidade da pessoa humana e da justiça social.

3 Nesse sentido, explica o autor Bruno Henrique da Silva Santos: "é nítido o intento do constituinte de delegar à lei ordinária a regulamentação do benefício assistencial previsto no artigo 203, V, da CF, uma vez que a redação do dispositivo é clara no sentido de que os requisitos necessários à concessão da renda mensal de um salário mínimo serão estabelecidos 'conforme dispuser a lei"”. (SANTOS, 2005, p.2). 
6.214/2007; a LOAS foi, na sequência, novamente alterada pelo Decreto $\mathrm{n}^{\circ}$ 6.564/2008 e, recentemente, modificada substancialmente pelas Leis 12.435/2011 e 12.470/2011, que perfazem a versão atualmente em vigor. ${ }^{4}$ Fundamental para a organização da Assistência Social brasileira e, principalmente, para a implementação do benefício de prestação continuada, a LOAS cumpriu com a incumbência de efetivar o dispositivo constitucional estabelecendo critérios para a concessão e, consequentemente, limitando o acesso da população ao benefício.

Em atendimento e complementação ao teor do artigo 203, inciso V, da Constituição de 1988, a Lei n ${ }^{\circ} 8.742 / 93$ estabelece, em seu artigo 20 (mesmo com a nova redação conferida pela Lei 12.435/2011), que o benefício assistencial, no valor de um salário mínimo nacional, será prestado - mensal e sucessivamente - à pessoa com deficiência ou idoso que não possua meios de prover sua própria manutenção, e nem tê-la provida com auxílio de sua família, desde que: esteja incapacitado para o trabalho e para atos da vida independente por dois anos ou mais; possua renda familiar mensal per capita inferior a 1/4 (um quarto) do salário mínimo vigente; e, não receba qualquer outro benefício da Seguridade Social ou de outro regime, de espécie alguma, salvo assistência médica. ${ }^{5}$

\footnotetext{
${ }^{4}$ Recentemente, em 6 de julho de 2015, aprovou-se a Lei n ${ }^{\circ}$ 13.146/2015 (Estatuto da Pessoa com Deficiência), que, decorrido o período de Vacatio Legis de 180 (cento e oitenta dias), modificará os $\S 2^{\circ}$ e $9^{\circ}$ do artigo 20 da LOAS, também incluindo em seu texto o $\S 11^{\circ}$.

"Art. 20. O benefício de prestação continuada é a garantia de um salário-mínimo mensal à pessoa com deficiência e ao idoso com 65 (sessenta e cinco) anos ou mais que comprovem não possuir meios de prover a própria manutenção nem de têla provida por sua família. (Redação dada pela Lei $n^{\circ} 12.435$, de 2011); $\S 1^{\mathrm{O}}$ Para os efeitos do disposto no caput, a-família é composta pelo requerente, o cônjuge ou companheiro, os pais e, na ausência de um deles, a madrasta ou o padrasto, os irmãos solteiros, os filhos e enteados solteiros e os menores tutelados, desde que vivam sob o mesmo teto. (Redação dada pela Lei $n^{\circ} 12.435$, de 2011); $\$ 2^{\circ}$ Para efeito đe concessão deste benefício, considera-se pessoa com deficiência aquela que tem impedimentos de longo prazo de natureza física, mental, intelectual ou sensorial, os quais, em interação com diversas barreiras, podem obstruir sua participação plena e efetiva na sociedade em igualdade de condições com as demais pessoas. (Redação dada pela Lei n ${ }^{\circ} 12.470$, de 2011 ); $\$ 3^{\circ}$ Considerase incapaz de prover a manutenção da pessoa com deficiência ou idosa a família cuja renda mensal per capita seja inferior a 1/4 (um quarto) do salário-mínimo. (Redação dada pela Lei $n^{\circ} 12.435$, de 2011); $\S 4^{\mathrm{O}}$ O benefício de que trata este artigo não pode ser acumulado pelo beneficiáriō com qualquer outro no âmbito da seguridade social ou de outro regime, salvo os da assistência médica e da pensão especial de natureza indenizatória. (Redação dada pela Lei $n^{\circ} 12.435$, de 2011); $\$ 5^{\circ}$ A condição de acolhimento em instituições de longa permanência não prejudica o direito do idoso ou da pes̄soa com deficiência ao benefício de prestação continuada. (Redação dada pela Lei $n^{\circ} 12.435$, de 2011); $\$ 6^{\circ}$ A concessão do benefício ficará sujeita à avaliação da deficiência e do grau de impedimento de que trata o $\S 2^{\circ}$, composta por avaliação médica e avaliação social realizadas por médicos peritos e por assistentes sociais do Instituto Nacional de Seguro Social - INSS. (Redação dada pela Lei $\mathrm{n}^{\mathrm{o}}$ 12.470, de 2011); $\S 7^{\mathrm{O}} \mathrm{Na}$ hipótese de não existirem serviços no município de residência do beneficiário, fica assegurado, na forma prevista em regulamento, o seu encaminhamento ao município mais próximo que contar com tal estrutura. (Incluído pela Lei $\mathrm{n}^{\circ}$ 9.720, de

30.11.1998); $\S 8^{\mathrm{O}}$-A renda familiar mensal a que se refere o $\S 3^{\mathrm{O}}$ deverá ser declarada pelo requerente ou seu representante legal, sujeitando-se aos demais procedimentos previstos no regulamento para o deferimento do pedido.(Incluído pela Lei $\mathrm{n}^{\circ}$ 9.720, de 30.11.1998); $9^{\circ}$ A remuneração da pessoa com deficiência na condição de aprendiz não será considerada para fins do cálculo a que se refere o $\S 3^{\circ}$ deste artigo. (Incluído pela Lei $n^{\circ}$ 12.470 , de 2011); $\S 10$. Considera-se impedimento de longo prazo, para os fins do $\S 2^{\mathrm{O}}$ deste artigo, aquele que produza efeitos pelo prazo mínimo de 2 (dois) anos. (Incluído pela Lei n 12.470 , de 2011 )”.
} 
Trata-se de direito de caráter personalíssimo, portanto, intransferível. Com isso, a concessão do benefício deverá ser revista a cada 2 (dois) anos e a morte do titular leva à extinção imediata, sem gerar direito à pensão por morte. Existem, ainda, outros fatores que remetem ao cancelamento do benefício, quais sejam: a cessação da incapacidade; a renda per capita da família superar o limite legal; e cumulatividade com outro benefício, salvo os de assistência médica. ${ }^{6}$

O benefício em questão é, pois, regulamentado pela Lei Orgânica da Assistência Social (LOAS), mantido pela União, gerido pelo Ministério do Desenvolvimento Social e Combate à Fome e operacionalizado pelo Instituto Nacional do Seguro Social (INSS). Os recursos destinados aos seus beneficiários são provenientes do Fundo Nacional de Assistência Social e, em 2013, aproximadamente R \$ 31,1 bilhões foram utilizados para assistir aproximadamente quatro milhões de pessoas, montante que representou o equivalente a $0,7 \%$ do PIB e $4,77 \%$ do orçamento da Seguridade Social (ANFIP, 2014).

Colocadas estas premissas iniciais, atentando para as características elencadas no artigo 203, inciso V, faz-se imprescindível estabelecer uma definição exata dos requisitos que são considerados no processo de concessão do benefício, quais sejam: a) condição pessoal do requerente (idade avançada ou constatação de deficiência); b) condição econômica do potencial beneficiário e de seu núcleo familiar (comprovação de hipossuficiência), c) composição da unidade familiar para fins de verificação do nível de carência econômica.

Destarte, a fim de melhor compreender todos os critérios essenciais à concessão do benefício, é preciso desmembrar esta lista de requisitos e analisá-los individualmente. Deste modo, inicia-se abordando a condição pessoal do requerente, que deve estar enquadrada em uma das seguintes hipóteses: idoso ou pessoa com deficiência e, conforme ensina Sérgio Fernando Moro (2002, p. 685-686), "Idosos e deficientes físicos constituem grupos especialmente vulneráveis, seja pela sua dificuldade de inserção no mercado de trabalho, seja por possuírem necessidades especiais [...], como gastos elevados em saúde”.

Quando da promulgação da LOAS, era considerada idosa a pessoa com 70 (setenta) anos ou mais; passando para 67 (sessenta e sete) anos por força da Lei 9.720/98 e, desde o advento do Estatuto do Idoso (Lei 10.741/2003), a idade foi diminuída para 65 (sessenta e cinco) anos, idade hoje expressamente adotada nos termos do artigo 20 da LOAS.

\footnotetext{
6 “Art. 21: O benefício de prestação continuada deve ser revisto a cada 2 (dois) anos para avaliação da continuidade das condições que lhe deram origem. $\S 1^{\circ} \mathrm{O}$ pagamento do benefício cessa no momento em que forem superadas as condições referidas no caput, ou em caso de morte do beneficiário. $\S 2^{\circ} \mathrm{O}$ benefício será cancelado quando se constatar irregularidade na sua concessão ou utilização".
} 
Já no que tange à caracterização de pessoa com deficiência, não importa a idade. De outro lado, as normas infraconstitucionais vêm tentando conceituar 'incapacidade' para fins de enquadramento nas disposições da LOAS.

O indivíduo deficiente, físico ou mental, deve comprovar que sua moléstia incapacitante obsta a inserção no mercado de trabalho, impossibilitando-o de prover seu próprio sustento. ${ }^{7}$ Veja-se que é exigida uma prova técnica que determine o grau (total ou parcial) e a duração (permanente ou temporária) da incapacidade - que deve perdurar por no mínimo 02 (dois) anos - porém, em nenhum momento a Lei determina que a moléstia deva ser irreversível.

Assim, em que pese o artigo 20, $\S 2^{\circ}$ da LOAS determinar que 'pessoa com deficiência' seria aquela que tem impedimentos que podem "obstruir sua participação plena e efetiva na sociedade", tem-se que a deficiência exigida pela Constituição de 1988 para fins da concessão do BPC não estabelece prazo mínimo de incapacidade e, tampouco, a cumulatividade de incapacidade para o trabalho $e$ para a vida independente ${ }^{8}$.

Isso porque, se a incapacidade laborativa - ainda que temporária - não for considerada suficiente, por si só, à concessão do benefício assistencial, muitas pessoas com deficiência ficarão totalmente desamparadas dentro do Sistema de Seguridade Social. É fato que tal incapacidade acaba por impedir a filiação desses indivíduos à Previdência, ao passo que a instituição de um critério altamente restritivo que impõe a cumulatividade de incapacidade para atos da vida independente $e$ para o trabalho, pelo prazo mínimo de 02 anos, retira o direito de proteção por meio da Assistência Social (MORO, 2003, p. 153).

À luz da doutrina e da jurisprudência, buscou-se modificar o caráter excludente estabelecido pelas normas valendo-se da interpretação constitucional, pois, como bem explica Melissa Folmann (2006, p. 375) "acolher posicionamento diverso seria deixar o cidadão que já possui problemas de inserção social, mais afastado ainda do dito Estado Social de Direito”.

No mesmo vértice, é entendimento sumulado da Turma Nacional de Uniformização dos Juizados Especiais (TNU): "Súmula n. 48: A incapacidade não precisa ser permanente para fins de concessão do benefício assistencial de prestação continuada”.

\footnotetext{
${ }^{7}$ Nos casos de deficiência em tenra idade (crianças e adolescentes até os dezesseis anos de idade) a incapacidade para o trabalho e para atos da vida independente deve ser presumida.

8 Segundo Melissa Folmann (2006, p. 374), antes da alteração do artigo 20, § $2^{\circ}$ da LOAS, a legislação que mais se aproximava do conceito constitucional de deficiência era o Decreto no 3.298 de 20 de dezembro de 1999 que define deficiência, em seu artigo 3o, inciso I, como sendo "toda perda ou anormalidade de uma estrutura ou função psicológica, fisiológica ou anatômica que gere incapacidade para o desempenho de atividade, dentro do padrão considerado normal para o ser humano".
} 
Em relação ao conceito de grupo familiar, considera-se para tanto o conjunto de pessoas que vivem na mesma residência, desde que elencadas no rol do artigo $20, \S 1^{\circ}$, da LOAS. Sobre o tema, merece destaque o entendimento de que a conceituação do grupo familiar deva ser obtida mediante uma interpretação restritiva do dispositivo legal supramencionado. Assim, somente o cônjuge; a companheira ou companheiro; os pais e, na ausência de um deles a madrasta ou o padastro; os irmãos solteiros; os filhos e enteados solteiros e menores tutelados, não emancipados, serão computados enquanto membros do núcleo familiar. ${ }^{9}$

Finalmente, conjugado a um desses fatores (idade ou deficiência), deve estar presente o requisito de carência econômica que, nos termos do artigo $20, \S 3^{\circ}$ da Lei 8.742/93, se configura pela comprovação de renda familiar per capita inferior a 1/4 (um quarto) do salário mínimo nacional. Importa salientar que este é um critério objetivo utilizado para determinar o grau de miserabilidade do indivíduo e, por consequência, aqueles que superam o limite imposto por lei, mas ainda assim se encontram em situação de necessidade e incapacitados para trabalhar, também ficam completamente desprotegidos dentro do sistema legal de Seguridade Social no Brasil (SAVARIS, 2009, p.11).

Feitas as considerações indispensáveis, segue o estudo com a abordagem específica do critério objetivo de miserabilidade previsto na LOAS enfocando, ainda, a disparidade existente entre a realidade socioeconômica dos potenciais beneficiários e a intenção da legislação brasileira.

\section{CRITÉRIO OBJETIVO DE MISERABILIDADE PREVISTO NA LOAS: REALIDADE SOCIOECONÔMICA DOS BENEFICIÁRIOS X LEGISLAÇÃO BRASILEIRA}

Além da incapacidade para o trabalho e demais requisitos já elencados, a pessoa com deficiência e o idoso que buscam a concessão do BPC devem comprovar que sua renda familiar per capita é inferior a $1 / 4$ (um quarto) do salário mínimo vigente, nos termos do artigo $20, \S 3^{\circ}$ da Lei $8.742 / 93$.

\footnotetext{
${ }^{9}$ É digna de nota a discussão existente nos tribunais com relação a este critério. Alguns juízes entendem que o conceito de família deve ser analisado no caso concreto, ante a possibilidade de o pretendente ao benefício assistencial residir com pessoas que, para fins da Lei 8.742/93, não integram o grupo familiar, mas têm possibilidade de prover o seu sustento. Nesses casos, existem entendimentos no sentido de aplicar objetivamente o rol do artigo 20, $\S 1^{\text {o }}$ da LOAS e desconsiderar a renda; e, de outro lado, entendimentos que consideram computável toda a renda advinda de pessoas que residam sobre o mesmo teto. Nesse sentido, preconiza o enunciado 51 do Fórum Nacional dos Juízes do Juizado Especial Federal (FONAJEF): “O artigo 20, parágrafo primeiro da Lei 8.742-93 não é exauriente para delimitar o conceito de unidade familiar". Disponível em: <http://www.trf4.jus.br>. Acesso em 15 jul. 2015.
} 
Atualmente, o salário mínimo nacional está fixado em R \$788,00 (setecentos e oitenta e oito reais). Por decorrência, a renda per capita familiar deve ser inferior a R $\$ 197,00$ (cento e noventa e sete reais) para atender o critério de miserabilidade, segundo previsão expressa da lei.

Ocorre que o requisito financeiro, em sua aplicação objetiva, restringe sobremaneira a camada social de pessoas aptas ao deferimento do benefício assistencial de prestação continuada e, consequentemente, a possibilidade de tutela de um direito social fundamental e de uma existência digna.

Diante disso, não se pode olvidar que a lei infraconstitucional tem respaldo para fixar os critérios objetivos para a concessão do BPC, pois, como exposto anteriormente, assim determinou a própria Constituição. No entanto, a aplicação desses critérios não deve ser feita de maneira absoluta e indiscriminada sob pena de distorcer o objetivo constitucional de amparo aos necessitados.

Com efeito, o que se defende atualmente é a possibilidade de análise das reais condições socioeconômicas da família - e não somente a aplicação do critério matemático da renda per capita - para, então, determinar o grau de necessidade do indivíduo de acordo com as particularidades de cada situação. Nesse sentido, explica Fábio Zambitte Ibrahim (2011, p. 14):

De fato, ainda que o Legislador frequentemente utilize-se de parâmetros objetivos para a fixação de direitos, a restrição financeira pode e deve ser ponderada com características do caso concreto, sob pena de condenar-se a morte o necessitado. Ainda que a extensão de benefício somente possa ser feita por lei, não deve o intérprete omitir-se à realidade social.

Do mesmo modo, em conformidade com o entendimento referenciado estão inúmeras decisões da Turma Nacional de Uniformização dos Juizados Especiais Federais do TRF da $4^{\mathrm{a}}$ Região e a jurisprudência reiterada do $\mathrm{STJ}^{10}$, que autoriza aferir a miserabilidade do idoso ou da pessoa com deficiência com base em outros elementos, como perícia e

10 BRASIL. Superior Tribunal de Justiça. AGRAVO REGIMENTAL EM RECURSO ESPECIAL. PREVIDENCIÁRIO. BENEFÍCIO DE PRESTAÇÃO CONTINUADA. AGRAVO REGIMENTAL. ART. 203, V, DA CF/88. ART. 20, § 3º, DA LEI 8.742/93. INCIDÊNCIA DOS VERBETES SUMULARES E 83/STJ. PRECEDENTES. 1. A Terceira Seção deste Superior Tribunal, no âmbito da Quinta e da Sexta Turma, consolidou entendimento de que a comprovação do requisito da renda familiar per capita não-superior a $1 \frac{1}{4}$ (um quarto)do salário mínimo não exclui outros fatores que tenham o condão de aferir a condição de miserabilidade da parte autora e de sua família, necessária à concessão do benefício assistencial. 2. A reapreciação do contexto fático-probatório em que se baseou o Tribunal de origem para deferir o benefício pleiteado, pela via do recurso especial, esbarra no óbice do enunciado sumular no 7/STJ. 3. Agravo regimental improvido. Ag Reg/RESP no. 529928/SP. Agravante: INSS. Agravado: Orlando Jacinto (representado). Relator: Ministro Arnaldo Esteves Lima. DJU 3/04/2006. 6 dez. 2005. Disponível em <http://www.stj.jus.br>. Acesso em: 13 jul. 2015. 
avaliação das circunstâncias concretas em cada caso. Em consonância com o posicionamento do STJ, afirma Magali Wickert (2008, p.8):

[...] sendo o Brasil um país continental, com muitas desigualdades regionais e sociais, um conceito único de miserabilidade pode gerar injustiças e excluir muitos indivíduos que, embora não se enquadrando no padrão fixado pela lei, ainda assim vivem em condições subumanas e necessitam do amparo da Assistência Social.

Corroborando a tese da autora, para demonstrar a existência de desigualdades regionais, pode-se citar a diferença do valor das cestas-básicas de acordo com a região do país, o custo de vida variável (gastos com alimentação e lazer, por exemplo) e, até mesmo, a considerável disparidade entre os salários mínimos regionais. ${ }^{11}$

Também a jurisprudência consolidada do Superior Tribunal de Justiça, defende o critério objetivo de 1/4 (um quarto) do salário mínimo como sendo um parâmetro base para a presunção legal da condição de miserabilidade do idoso ou da pessoa com deficiência e sua família. ${ }^{12}$ Assim, quando a renda do grupo familiar atender ao requisito de renda per capita, fica automaticamente presumida a situação de carência econômica, não sendo exigível qualquer outro elemento de prova. Caso contrário, confere-se a possibilidade de comprovar a real necessidade de amparo assistencial utilizando-se, para tanto, outros meios probatórios.

Além das considerações já expostas, importa ainda repisar que a renda considerada para fins de cálculo da per capita familiar é a renda mensal bruta, sem desconsiderar qualquer gasto habitual decorrente da situação particular do indivíduo, ou inerentes à moradia, alimentação, higiene pessoal, saúde, água, luz, etc. Sobre o tema, pondera Amartya Sen (2000, p. 110):

\begin{abstract}
Desvantagens como a idade, incapacidade ou doença reduzem o potencial do indivíduo para auferir renda. Mas, também, tornam mais difícil converter renda em capacidade, já que uma pessoa mais velha, mais incapacitada ou mais gravemente enferma pode necessitar de mais renda (para assistência, prótese, tratamento) para obter os mesmos funcionamentos [...].
\end{abstract}

\footnotetext{
${ }^{11}$ Diversos estudos que ilustram o assunto podem ser encontrados no website do Departamento Intersindical de Estatística e Estudos Socioeconômicos (DIEESE): <http://www.dieese.org.br/> .

12 E.g., BRASIL. Superior Tribunal de Justiça. Agravo Regimental no Recurso Especial. PREVIDENCIÁRIO. BENEFÍCIO ASSISTENCIAL. ART. 34 DA LEI N. 10.741/2003. INTERPRETAÇÃO RESTRITIVA. REQUISITOS. RENDA FAMILIAR. $1 / 4$ DE SALÁRIO MÍNIMO. PARÂMETRO MÍNIMO. MISERABILIDADE COMPROVADA. CONTEXTO FÁTICO. REEXAME. IMPOSSIBILIDADE. 1. A interpretação restritiva defendida pela Autarquia no tocante ao art. 34 da Lei n. 10.741/2003 está em sintonia com a jurisprudência desta Corte (AgRg no REsp $\left.n^{\circ} 868.590 / \mathrm{SP}\right)$. 2. Predomina no âmbito da egrégia Terceira Seção o entendimento de que o critério previsto no artigo $20, \S 3^{\circ}$, da Lei n. 8.742/1993 deve ser interpretado como limite mínimo. 3. A alteração da convicção firmada pelas instâncias ordinárias demanda o revolvimento do contexto fático dos autos e desafia a Súmula n. 7/STJ. 4. Agravo regimental improvido. Agravo Regimental no Recurso Especial $n^{\circ}$. 1.177.395/PR. Agravante: INSS. Agravado: Adriana Ferreira da Silva. Relator: Ministro Jorge Mussi. DJ 24/05/2010. Disponível em: 〈http://www.stj.jus.br〉. Acesso em: 12 jul. 2015.
} 
Por esse motivo, quando aplicado objetivamente o critério de miserabilidade, sem antes observar as peculiaridades do caso concreto, situações semelhantes na vida real acabam por receber tratamento distinto por força de Lei, causando inúmeras injustiças. A título de exemplo, vejamos a seguinte situação hipotética:

\begin{abstract}
1 - Uma determinada família composta pelos pais e três filhos, sendo um deles deficiente incapacitado para o trabalho e até mesmo para a vida independente, possui a renda mensal de apenas um salário mínimo. Nessa situação, a renda per capita de cada um dos membros da família é inferior a $1 / 4$ (um quarto) do salário mínimo, tendo o filho deficiente o direito de receber o benefício de prestação continuada. 2 - Uma outra família, com renda também de um salário mínimo, é composta por um casal de idosos com mais de 65 (sessenta e cinco) anos e um filho deficiente, incapaz da mesma maneira que aquele do exemplo anterior. Essa família possui gastos elevadíssimos e constantes com medicamentos utilizados pelos pais idosos e também pelo filho deficiente. Além disso, precisa pagar uma pessoa estranha à família que cuide diuturnamente do filho, diante da idade avançada dos pais, a qual impossibilita que eles proporcionem os devidos cuidados ao deficiente. Essa família, cuja necessidade de amparo é tão grande quanto ou maior do que a do exemplo anterior, não teria direito ao benefício assistencial de prestação continuada, caso se utilizasse de uma interpretação literal do art. $20, \S 3^{\circ}$, da Lei $n^{\circ} 8.742 / 93$, pois a renda per capita é superior a $1 \frac{1}{4}$ (um quarto) do salário mínimo (SANTOS, p.8, 2005).
\end{abstract}

É perceptível, portanto, que a simples inobservância ao valor de renda mensal per capita não é suficiente para determinar a ausência de necessidade da prestação assistencial. Desta feita, acertado o entendimento que interpreta o disposto no $\S 3^{\circ}$ do artigo 20 da LOAS à luz da Constituição Federal, respeitado o princípio fundamental da dignidade da pessoa humana e outros objetivos do Estado Democrático de Direito preconizados no artigo $3^{\circ}$ da Carta Magna.

Ademais, este rigor excessivo aplicado no momento da não concessão do BPC, inserido pela legislação infraconstitucional, representa um retrocesso social se comparado a dispositivos legais relativos à Assistência Social mais recentes, como as Leis no 9.533/97 e $\mathrm{n}^{\circ}$ 10.689/2003, que também condicionam um critério excludente, porém, de 1/2 (meio) salário mínimo nacional, aplicável para determinar o conceito de carência.

Destarte, há de se considerar a superveniência de fato novo e mais benéfico, postulado pelo próprio legislador. ${ }^{13}$ No contexto atual, o critério de miserabilidade de $1 / 4$ (um

\footnotetext{
${ }^{13}$ Sobre o tema, firmou orientação posteriormente cancelada a Turma Regional de Uniformização do Tribunal Regional Federal da $4^{a}$ Região (TRU): Súmula no 6: O critério de verificação objetiva da miserabilidade correspondente a $1 / 4$ (um quarto) do salário mínimo, previsto no art. $20, \S 3^{\circ}$, da Lei $n^{\circ} 8.742 / 93$, restou modificado para $1 \frac{1}{2}$ (meio) salário mínimo, a teor do disposto no art. $5^{\circ}$, I, da Lei no $9.533 / 97$, que autorizava o Poder Executivo a conceder apoio financeiro aos Municípios que instituíssem programas de garantia de renda mínima associados a ações socioeducativas, e art. $2^{\circ}, \S 2^{\circ}$, da Lei $n^{\circ} 10.689 / 2003$, que instituiu o Programa Nacional de Acesso à Alimentação - PNAA. (Cancelada em: 07/07/2006). Disponível em: $<$ http://www.trf4.jus.br>. Acesso em 15 jul. 2015.
} 
quarto) do salário mínimo vigente - estabelecido pela Lei 8.742/93 - se faz insuficiente para atestar a ausência de necessidade de percepção do benefício assistencial, porquanto a interpretação da legislação posterior determina um critério mais elástico para este mesmo fim.

Coerentemente, portanto, em que pese o disposto na legislação infraconstitucional, tem-se mantido entendimento doutrinário e jurisprudencial no sentido de conceder o benefício ainda que a renda familiar per capita ultrapasse o limite objetivo sempre que restar comprovada a situação de extrema carência econômica. Nesses casos, é necessário utilizar de outros elementos subjetivos hábeis a comprovar, no caso concreto, que o contexto socioeconômico em que se encontra o idoso ou a pessoa com deficiência evidencia a presença de risco social.

Feita esta análise e contextualizada a problemática utilizada como base no presente artigo, resta sintetizar os posicionamentos até hoje adotados pelo Supremo Tribunal Federal, revelando a atual concepção dada pela Suprema Corte à caracterização da situação de necessidade do indivíduo.

\section{A EVOLUÇÃO DE POSICIONAMENTO DO STF E A CONFIGURAÇÃO DA NECESSIDADE DO INDIVÍDUO.}

A fixação do chamado "critério de miserabilidade" deixou à margem do sistema muitas pessoas que não apresentam qualquer condição econômica de prover seu próprio sustento ou tê-lo provido por sua família, simplesmente porque recebem alguma renda e igualam, ou superam (ainda que infimamente), o limite legal estabelecido.

Objetivando solucionar a questão - amplamente discutida pela doutrina e nos Tribunais - da criação de um parâmetro adequado para a aferição da miserabilidade, o Procurador-Geral da República impetrou, em 1995, a Ação Direta de Inconstitucionalidade (ADI) n ${ }^{\circ} 1.232-1 /$ DF. $^{14}$ Sob a alegação de inconstitucionalidade do dispositivo legal constante do artigo $20, \S 3^{\circ}$ da Lei $8.742 / 93$, porquanto limitador e restritivo de direito garantido por norma constitucional, qual seja, o artigo 203 da Carta Magna vigente, a matéria chegou ao

STF.

\footnotetext{
14 BRASIL. Supremo Tribunal Federal. Ação Direta de Inconstitucionalidade. Constitucional. Impugna dispositivo de lei federal que estabelece o critério para receber o benefício do inciso V do art. 203 da CF. Inexiste a restrição alegada em face do próprio dispositivo constitucional que reposta à lei para fixar os critérios de garantia do benefício de salário mínimo à pessoa portadora de deficiência física e ao idoso. Esta lei traz hipótese objetiva de prestação assistencial do estado. Ação julgada improcedente. ADI no 1.232 - DF. Requerente: Procurador-Geral da República. Requerido: Presidente da República; Congresso Nacional. Relator: Min.

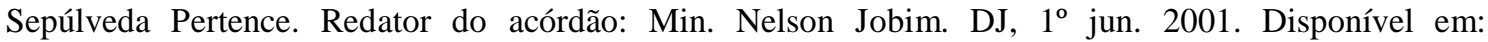
<http://www.stf.jus.br>. Acesso em: 02 jul. 2015.
} 
O Supremo Tribunal, por sua vez, concluiu pela constitucionalidade da norma em questão, especialmente por entender que o dispositivo constante da Constituição da República não deixa dúvidas no sentido de que a fixação de parâmetros para a concessão do benefício assistencial foi atribuído à lei infraconstitucional. Por ocasião do julgamento, votaram 6 (seis) Ministros, sendo que a ação restou julgada improcedente por maioria de votos.

Contudo, mister destacar que de uma análise pormenorizada dos votos proferidos na ocasião percebe-se que os integrantes do Supremo Tribunal não chegaram sequer a aventar que o critério de $1 / 4$ ( um quarto) do salário mínimo deveria ser tido como elemento exclusivo para definir a condição de necessidade do sujeito que pleiteia o benefício assistencial. Do contrário, assim revelam as considerações do então Relator - vencido em parte - Ministro Ilmar Galvão:

[...] Na realidade, não se pode vislumbrar inconstitucionalidade no texto legal, posto revelar ele uma verdade irrefutável, seja, a de que é incapaz de prover a manutenção da pessoa portadora de deficiência ou idosa a família cuja renda mensal per capita seja inferior a 1/4 do salário mínimo. A questão que resta é a de saber se com a hipótese prevista pela norma é a única suscetível de caracterizar a situação de incapacidade econômica da família do portador de deficiência ou do idoso inválido. Revelando-se manifesta a impossibilidade da resposta positiva, que afastaria grande parte dos destinatários do benefício assistencial previsto na Constituição, outra alternativa não resta senão empresar ao texto impugnado interpretação segundo a qual não limita ele os meios de prova da condição de miserabilidade da família do necessitado deficiente ou idoso. [...]. (ADI no ${ }^{\circ} 1.232$ - DF. Requerente: Procurador- Geral da República. Requerido: Presidente da República; Congresso Nacional. Relator: Min. Sepúlveda Pertence. Redator do acórdão: Min. Nelson Jobim. DJ 01/06/2001).

$\mathrm{Na}$ mesma linha, o Ministro Sepúlveda Pertence consignou em voto vislumbrar a parcial omissão legislativa quanto ao cumprimento do artigo 203, inciso V, da Constituição da República:

[...] considero perfeita a inteligência dada ao dispositivo constitucional, [...], no sentido de que o legislador deve estabelecer outras situações caracterizadoras da absoluta incapacidade de manter-se o idoso ou deficiente físico, a fim de completar a efetivação do programa normativo de assistência contido no art. 203 da Constituição. A meu ver, isso não a faz inconstitucional nem é preciso dar interpretação conforme à lei que estabeleceu uma hipótese objetiva de direito à prestação assistencial do Estado. Haverá, aí, inconstitucionalidade por omissão de outras hipóteses? A meu ver, certamente sim, mas isso não encontrará remédio nesta ação direta. (ADI nº. 1.232 - DF. Requerente: Procurador-Geral da República. Requerido: Presidente da República; Congresso Nacional. Relator: Min. Sepúlveda Pertence. Redator do acórdão: Min. Nelson Jobim. DJ 01/06/2001).

Porém, em que pese a ressalva feita por alguns Ministros apontando possível omissão 
- inconstitucional - parcial do artigo $20, \S 3^{\circ}$ da Lei 8.742/93, fato é que a posição adotada pela maioria dos integrantes do Supremo Tribunal quando do julgamento da referida ADI prevaleceu e, sem que o legislador se pronunciasse sobre o tema, restou assentado que o critério econômico objetivo era hígido e, portanto, deveria ser aplicado em regime exclusivo até a criação de novos parâmetros legais para aferição do estado de pobreza do indivíduo.

A despeito do entendimento então consolidado na Suprema Corte, as injustiças ocasionadas pela aplicação de critério matemático para a mensuração da miserabilidade repercutiram em imediata resistência das instancias inferiores. $\mathrm{O}$ impasse perdurou por muitos anos e foi amplamente debatido em outras oportunidades, mas o STF continuou mantendo sua decisão. ${ }^{15}$ Assim, como bem sintetizado pelo Ministro Gilmar Mendes em análise retrospectiva:

[...] Entre aplicar friamente o critério objetivo da lei e adotar a solução condizente com a realidade social da família brasileira, os juízes permaneceram abraçando a segunda opção, mesmo que isso significasse a criação judicial de outros critérios não estabelecidos em lei e, dessa forma, uma possível afronta à decisão do STF. [...] A situação foi extremamente propícia para que começasse a aportar no Supremo Tribunal Federal uma verdadeira enxurrada de reclamações movidas pelo Instituto Nacional do Seguro Social (INSS). O Tribunal então passou a julgar procedentes tais reclamações para cassar decisões, proferidas pelas instâncias jurisdicionais inferiores, que concediam o benefício assistencial entendendo que o requisito definido pelo $\S 3^{\circ}$ do art. 20 da Lei 8.742/93 não é exaustivo e que, portanto, o estado de miserabilidade poderia ser comprovado por outros meios de prova. [...] o STF manteve seu entendimento, mesmo nas reclamações ajuizadas contra decisões que, procedendo a uma interpretação sistemática das leis sobre a matéria, concediam o benefício assistencial com base em outros critérios estabelecidos por alterações legislativas posteriores. [...] Mas, as reiteradas decisões do STF não foram suficientes para coibir as decisões das instâncias inferiores na solução dos casos concretos. A inventividade hermenêutica passou a ficar cada vez mais apurada, tendo em vista a necessidade de se escapar dos comandos impostos pela jurisprudência do STF. (STF. Reclamação $\mathrm{n}^{\circ}$. 4374-PE. Reclamante: INSS. Reclamado: Turma Recursal dos Juizados Especiais Federais do Estado de Pernambuco. Relator: Ministro Gilmar Mendes. DJ 04/09/2013).

Destarte, atentando para a tenaz discussão doutrinária e jurisprudencial acerca do tema, a partir do ano de 2006, os Ministros da Suprema Corte passaram a rever posicionamentos anteriores e, mesmo sem alcançar uma uniformidade de entendimento, alteraram consideravelmente o cenário.

Sem adentrar no mérito, mas utilizando subterfúgios processuais, os Ministros Celso de Mello, Carlos Britto e Ricardo Lewandowski adotaram fundamentação de que a Reclamação (instrumento utilizado pelo INSS) não era via adequada para reexame de conjunto fático-probatório e, portando, não deveria ser conhecida. ${ }^{16}$ Concomitantemente, o

\footnotetext{
15 V., por exemplo, as Reclamações 2.303/RS de relatoria da Min. Ellen Gracie (DJ 1.4.2005) e 2.323/PR de relatoria do Min. Eros Grau (DJ 20.5.2005).

16 Nesse sentido, v., a título ilustrativo, as Reclamações 4.422/RS de relatoria do Min. Celso de Mello (DJ 30.6.2006); 4.133/RS, de relatoria do Min. Carlos Britto (DJ 30.6.2006); e 4.366/PE de relatoria do Min. Ricardo Lewandowski (DJ 01.6.2006).
} 
Ministro Marco Aurélio reiterava posicionamento de insuficiência dos critérios previstos na legislação infraconstitucional para a devida observância do dispositivo inserto na Constituição. ${ }^{17}$ Isso porque, como visto, a possibilidade de conjugar outros meios a fim de determinar o nível de carência no caso concreto não foi objeto de análise na Suprema Corte. De igual forma, decidia a Ministra Cármen Lúcia, in verbis:

[...] O pedido de declaração de constitucionalidade do art. $20, \S 3^{\circ}$, da Lei $8.742 / 92$, parece-me impertinente, na medida em que este Supremo Tribunal já o fez por ocasião do julgamento da Ação Direta de Inconstitucionalidade no 1.232-DF. De se concluir, entretanto, que o Supremo Tribunal teve por constitucional, em tese (cuidavase de controle abstrato), a norma do art. 20 da Lei $n^{\circ} 8.742 / 93$, mas não afirmou inexistirem outras situações concretas que impusessem atendimento constitucional e não subsunção àquela norma. A constitucionalidade da norma legal, assim, não significa a inconstitucionalidade dos comportamentos judiciais que, para atender, nos casos concretos, à Constituição, garantidora do princípio da dignidade humana e do direito à saúde, e à obrigação estatal de prestar a assistência social "a quem dela necessitar, independentemente da contribuição à seguridade social", tenham de definir aquele pagamento diante da constatação da necessidade da pessoa portadora de deficiência ou do idoso que não possa prover a própria manutenção ou de tê-la provida por sua família. [ ] Quer o INSS, ora Agravante, se considere ser a definição do benefício concedido à Agravada incompatível com o quanto decidido na Ação Direta de Inconstitucionalidade 1.232. Não é o que se tem no caso. Afirmo: e a miséria constatada pelo juiz é incompatível com a dignidade da pessoa humana, princípio garantido no art. $1^{\circ}$, inc. III, da Constituição da República; e a política definida a ignorar a miserabilidade de brasileiros é incompatível com os princípios postos no art. $3^{\circ}$ e seus incisos da Constituição; e a negativa do Poder Judiciário em reconhecer, no caso concreto, a situação comprovada e as alternativas que a Constituição oferece para não deixar morrer à mingua algum brasileiro é incompatível com a garantia da jurisdição, a todos assegurada como direito fundamental (art. $5^{\circ}$, inc. XXXV, da Constituição da República). (STF. Agravo Regimental no Agravo de Instrumento $n^{\circ}$ 470.975-6/SP. Agravante: INSS. Agravado: Diamantina Gonçalves dos Santos. Relatora: Ministra Cármen Lúcia. DJ 18/12/2006)

Por sua vez, o Ministro Sepúlveda Pertence, afirmava que as interpretações dadas nas decisões reclamadas não afrontavam o anterior entendimento do STF quanto à constitucionalidade do critério objetivo de renda per capita enquanto requisito indispensável para a concessão do BPC, mas apenas levavam em consideração a intenção do legislador de classificar como carentes para fins de prestações assistenciais famílias com renda per capita de até 1/2 (meio) salário mínimo, conforme estabelecido em alterações legislativas posteriores, que não foram objeto da $\mathrm{ADI} \mathrm{n}^{\circ} 1.232-1 / \mathrm{DF}^{18}$

\footnotetext{
${ }^{17} V$. Reclamação 4.164/RS, de relatoria do Min. Marco Aurélio (DJ 29.5.2006).

${ }^{18}$ V. Reclamação 4.280/RS, de relatoria do Min. Sepúlveda Pertence (DJ 30.6.2006).
} 
Também nesse sentido e, ainda, indicando novamente a possibilidade de conjugar e analisar outros elementos com vistas a demonstrar à presença de hipossuficiência, passou a sustentar o Ministro Gilmar Mendes:

[...] De fato, não se pode negar que a superveniência de legislação que estabeleceu novos critérios mais elásticos para a concessão de outros benefícios assistenciais como a Lei $n^{\circ} 10.836 / 2004$, que criou o Bolsa Família; a Lei $n^{\circ} 10.689 / 2003$, que instituiu o Programa Nacional de Acesso à Alimentação; a Lei no 10.219/01, que criou o Bolsa Escola; a Lei n ${ }^{\circ} 9.533 / 97$, que autoriza o Poder Executivo a conceder apoio financeiro a Municípios que instituírem programas de garantia de renda mínima associados a ações socioeducativas; assim como o Estatuto do Idoso (Lei $\mathrm{n}^{\circ}$

10.741/03) - está a revelar que o próprio legislador tem reinterpretado o art. 203 da Constituição Federal. [...] O Tribunal parece caminhar no sentido de se admitir que o critério de $1 / 4$ do salário mínimo pode ser conjugado com outros fatores indicativos do estado de miserabilidade do indivíduo e de sua família para concessão do benefício assistencial de que trata o art. 203, inciso V, da Constituição. [...] Os inúmeros casos concretos que são objeto do conhecimento dos juízes e tribunais por todo o país, e chegam a este Tribunal pela via da reclamação ou do recurso extraordinário, têm demonstrado que os critérios objetivos estabelecidos pela Lei $\mathrm{n}^{\circ}$ 8.742/93 são insuficientes para atestar que o idoso ou o deficiente não possuem meios de prover à própria manutenção ou de tê-la provida por sua família. Constatada tal insuficiência, os juízes e tribunais nada mais têm feito do que comprovar a condição de miserabilidade do indivíduo que pleiteia o benefício por outros meios de prova. Não se declara a inconstitucionalidade do art. $20, \S 3^{\circ}$, da Lei

8.742/93, mas apenas se reconhece a possibilidade de que esse parâmetro objetivo seja conjugado, no caso concreto, com outros fatores indicativos do estado de penúria do cidadão. [...] A meu ver, toda essa reinterpretação do art. 203 da Constituição, que vem sendo realizada tanto pelo legislador como por esta Corte, pode ser reveladora de um processo de inconstitucionalização do $\S 3^{\circ}$ do art. 20 da Lei $n^{\circ}$ 8.742/93. Diante de todas essas perplexidades sobre o tema, é certo que o Plenário do Tribunal terá de enfrentá-lo novamente. (STF. Medida Cautelar na Reclamação nº 4.374-PE. Reclamante: INSS. Reclamado: Turma Recursal dos Juizados Especiais Federais do Estado de Pernambuco. Relator: Ministro Gilmar Mendes. DJ 06/02/2007).

Desta feita, não obstante o STF ter anteriormente reconhecido a constitucionalidade do $\S 3^{\circ}$ do artigo 20 da Lei 8.742/1993, sabendo que esta não era a posição final da Suprema Corte no que se refere à aferição da miserabilidade, sedimentou-se o entendimento de que o valor estipulado como limite de renda para fins da concessão do benefício de prestação continuada é ínfimo; e completamente insuficiente no contexto da realidade social brasileira. Exatamente por tal motivo a matéria não restou pacificada, voltando a ser objeto de discussão perante o Supremo Tribunal Federal.

Com repercussão geral admitida pelo STF em 2008, a questão foi reexaminada em sede de Recurso Extraordinário. Coerentemente, o voto proferido pelo então Relator, Ministro Marco 
Aurélio, manteve o entendimento de insuficiência do critério econômico da renda per capita em valor inferior a 1/4 do salário mínimo para configuração da necessidade do indivíduo. Nesse sentido, merecem destaque alguns trechos de alta consistência jurídica e social do voto:

[...] Em suma, está-se diante de situação em que a concretização do princípio da dignidade humana e do dever específico de proteção dos hipossuficientes - idosos e deficientes - encontra-se aquém do texto constitucional. Embora ainda pouco utilizado pelo Supremo, emerge como parâmetro de aferição de constitucionalidade da intermediação legislativa de direitos fundamentais o chamado princípio da concretização deficitária, cujo fundamento último radica-se no dever, imputável ao Estado, de promover a edição de leis e ações administrativas efetivas para proteger os direitos fundamentais [...]. Com base em alguns fundamentos, entendo ser possível assentar a prevalência da leitura constitucional impugnada pela recorrente sobre tais elementos sistêmicos. Como já relatado, a decisão veiculada na regra infralegal não se sobrepõe à estampada na Carta Federal. No confronto de visões, há de prevalecer aquela que melhor concretiza o princípio constitucional da dignidade humana - cuja aplicação é prioritária no ordenamento jurídico. Quanto às considerações concernentes à segurança jurídica e isonômica, também elas hão de ceder frente àquele princípio maior. Descabe comungar com enfoque que, a pretexto de assegurar as expectativas no tocante à aplicação do Direito, acaba por a colocar seres humanos na mais completa situação de indignidade. (Recurso Extraordinário $\mathrm{n}^{\circ}$. 567.985. Reclamante: INSS. Reclamado: Alzira Maria de Oliveira Souza. Relator: Ministro Marco Aurélio. Redator do Acórdão: Min. Gilmar Mendes. DJ 02/08/2013).

Em julgamento realizado no ano de 2013, a Corte - por maioria - declarou, incidenter tantum, a inconstitucionalidade parcial do $\S 3^{\circ}$ do artigo 20 da LOAS, deixando de pronunciar a nulidade da regra. O acórdão foi redigido pelo Ministro Gilmar Mendes, que também propôs a fixação de prazo para que o Congresso Nacional regulamentasse a matéria. A proposta, porém, não alcançou a adesão do quórum mínimo e a modulação dos efeitos da decisão, para que a norma em apreço tivesse validade até 31/12/2015, restou prejudicada.

Confirmando o posicionamento já consolidado pelo Plenário, com o julgamento da Reclamação $n^{\circ}$ 4.374/PE - também por maioria - o STF reiterou a inconstitucionalidade parcial da previsão legal referente ao critério objetivo de miserabilidade. Em seu voto, o Relator, Ministro Gilmar Mendes, reformulou radicalmente o entendimento fixado por ocasião da ADI no 1.232-1/DF. É o que se extrai dos principais trechos da ementa:

Benefício assistencial de prestação continuada ao idoso e ao deficiente. Art. 203, V, da Constituição. A Lei de Organização da Assistência Social (LOAS), ao regulamentar o art. 203, V, da Constituição da República, estabeleceu critérios para que o benefício mensal de um salário mínimo fosse concedido aos portadores de deficiência e aos idosos que comprovassem não possuir meios de prover a própria manutenção ou de tê-la provida por sua família. 2 . Art. $20, \S 3^{\circ}$ da Lei 8.742/1993 e a declaração de constitucionalidade da norma pelo Supremo 
Tribunal Federal na ADI 1.232. Dispõe o art. 20, $\S 3^{\circ}$, da Lei 8.742/93 que "considera-se incapaz de prover a manutenção da pessoa portadora de deficiência ou idosa a família cuja renda mensal per capita seja inferior a $1 / 4$ (um quarto) do salário mínimo". O requisito financeiro estabelecido pela lei teve sua constitucionalidade contestada, ao fundamento de que permitiria que situações de patente miserabilidade social fossem consideradas fora do alcance do benefício assistencial previsto constitucionalmente. Ao apreciar a Ação Direta de Inconstitucionalidade 1.232-1/DF, o Supremo Tribunal Federal declarou a constitucionalidade do art. $20, \S 3^{\circ}$, da LOAS. 3. Reclamação como instrumento de (re)interpretação da decisão proferida em controle de constitucionalidade abstrato. [...] 4. Decisões judiciais contrárias aos critérios objetivos preestabelecidos e Processo de inconstitucionalização dos critérios definidos pela Lei 8.742/1993. A decisão do Supremo Tribunal Federal, entretanto, não pôs termo à controvérsia quanto à aplicação em concreto do critério da renda familiar per capita estabelecido pela LOAS. Como a lei permaneceu inalterada, elaboraram-se maneiras de contornar o critério objetivo e único estipulado pela LOAS e avaliar o real estado de miserabilidade social das famílias com entes idosos ou deficientes. Paralelamente, foram editadas leis que estabeleceram critérios mais elásticos para concessão de outros benefícios assistenciais, tais como: a Lei 10.836/2004, que criou o Bolsa Família; a Lei 10.689/2003, que instituiu o Programa Nacional de Acesso à Alimentação; a Lei 10.219/01, que criou o Bolsa Escola; a Lei 9.533/97, que autoriza o Poder Executivo a conceder apoio financeiro a municípios que instituírem programas de garantia de renda mínima associados a ações socioeducativas. O Supremo Tribunal Federal, em decisões monocráticas, passou a rever anteriores posicionamentos acerca da intransponibilidade dos critérios objetivos. Verificou-se a ocorrência do processo de inconstitucionalização decorrente de notórias mudanças fáticas (políticas, econômicas e sociais) e jurídicas (sucessivas modificações legislativas dos patamares econômicos utilizados como critérios de concessão de outros benefícios assistenciais por parte do Estado brasileiro). 5. Declaração de inconstitucionalidade parcial, sem pronúncia de nulidade, do art. 20, $\S 3^{\circ}$, da Lei 8.742/1993. 6. Reclamação constitucional julgada improcedente. (Reclamação ${ }^{\circ}$ 4.374-PE. Reclamante: INSS. Reclamado: Turma Recursal dos Juizados Especiais Federais do Estado de Pernambuco. Relator: Ministro Gilmar Mendes. DJ 04/09/2013).

Como visto, o histórico de concessão judicial do benefício assistencial mesmo ante a ausência do critério objetivo para aferição da miserabilidade ressoou na jurisprudência do STF e, pelas considerações acima expostas, resta claro que muitos eram os motivos que justificavam a reapreciação da matéria pelo Pleno do Supremo Tribunal.

A evolução de posicionamento do STF permitiu rever a intransponibilidade do dispositivo infraconstitucional que determinava parâmetro econômico de 1/4 do salário mínimo para configuração de miserabilidade e culminava, muitas vezes, no indeferimento da concessão do benefício a indivíduos que verdadeiramente carecem de proteção.

Em síntese conclusiva, o atual entendimento da Suprema Corte brasileira reconhece a impossibilidade de fixação de critério objetivo imutável para fins de aferição do estado de miserabilidade econômica e legitima o juiz que, conjugando outros meios probatórios para comprovação da hipossuficiência, determinará o efetivo direito ao amparo assistencial frente ao caso concreto. 


\section{CONSIDERAÇÕES FINAIS}

Ao longo do trabalho, buscou-se apresentar ao leitor uma síntese da previsão constitucional do benefício de prestação continuada e da regulamentação dos requisitos exigidos para sua concessão conforme o disposto na Lei Orgânica da Assistência Social, enfocando especificamente o critério objetivo de miserabilidade previsto na legislação infraconstitucional e, assim, o descompasso existente entre a realidade socioeconômica dos beneficiários e o disposto em Lei.

Do estudo, que sustenta como principal objetivo demonstrar - sem pretensão de exaurir a matéria - os diferentes posicionamentos já sustentados pelo STF no enfrentamento da problemática envolvendo o critério de miserabilidade positivado na LOAS, evidenciando o atual entendimento da Suprema Corte brasileira sobre a configuração da situação de necessidade do indivíduo, restaram as seguintes conclusões:

1. O critério de carência econômica previsto na legislação infraconstitucional impõe rigor excessivo e a sua aplicação objetiva acaba por desconsiderar as condições da realidade social no momento da não concessão do benefício. Emerge, aqui, um descompasso entre a realidade socioeconômica dos beneficiários e a legislação brasileira;

2. Em virtude do câmbio substancial da realidade fática, política, socioeconômica e jurídica da norma infraconstitucional desde sua edição - em 1993 - e de seu anterior julgamento pela Suprema Corte, há mais de uma década, o parâmetro econômico de 1/4 do salário mínimo per capita foi recentemente considerado defasado para qualificar situação de miserabilidade do indivíduo;

3. Nesse contexto, não obstante o Supremo Tribunal Federal tenha anteriormente reconhecido a constitucionalidade do $\S 3^{\circ}$ do artigo 20 da LOAS, a evolução de posicionamento permitiu rever a intransponibilidade do dispositivo infraconstitucional e, revisitando a matéria, o STF declarou inconstitucional o critério econômico objetivo até então previsto como limitador à concessão do benefício assistencial;

4. $\mathrm{O}$ atual entendimento da Suprema Corte brasileira no que se refere à configuração da necessidade do indivíduo reconhece: i) a impossibilidade de fixação de critério objetivo imutável para fins de aferição do estado de miserabilidade econômica; e ii) a 
essencialidade de conjugação de outros meios probatórios para comprovação do efetivo direito ao amparo assistencial frente ao caso concreto.

\section{REFERÊNCIA BIBLIOGRÁFICA}

ASSOCIAÇÃO NACIONAL DOS AUDITORES-FISCAIS DA RECEITA FEDERAL DO BRASIL - ANFIP. Análise da Seguridade Social 2013. Brasília: Fundação ANFIP, 2014. Disponível em: <http://www.anfip.org.br/publicacoes/20140903125923_Analise-daSeguridade-Social-2013_03-09-2014_Anlise-da-SS-2013-ntegra.pdf>. Acesso em: 27 jun. 2015.

BRASIL. Constituição (1988). Constituição da República Federativa do Brasil. Diário Oficial [da] República Federativa do Brasil, Brasília, DF, 05 out. 1988. Disponível em: < http://www.planalto.gov.br/ccivil_03/constituicao/constituicao.htm>. Acesso em: 15 jun. 2015.

Decreto $\mathrm{n}^{\circ}$. 6.214, de 26 de setembro de 2007. Regulamenta o benefício de prestação continuada da assistência social devido à pessoa com deficiência e ao idoso de que trata a Lei $n^{\circ} 8.742$, de 7 de dezembro de 1993, e a Lei $n^{\circ} 10.741$, de $1^{\circ}$ de outubro de 2003, acresce parágrafo ao art. 162 do Decreto $\mathrm{n}^{\circ} 3.048$, de 6 de maio de 1999, e dá outras providências. Diário Oficial [da] República Federativa do Brasil. Brasília, DF, 28 set. 2007. Disponível em: <http://www.planalto.gov.br/ccivil_03/_ato2007-2010/2007/decreto/ d6214.htm>. Acesso em: 30 jun. 2015.

Decreto $n^{\circ}$. 6.564/2008, de 12 de setembro de 2008. Altera o Regulamento do Benefício de Prestação Continuada, aprovado pelo Decreto $n^{\circ}$. 6.214, de 26 de setembro de 2007, e dá outras providências. Diário Oficial [da] República Federativa do Brasil. Brasília, DF, 15 set. 2008. Disponível em: <http://www.planalto.gov.br/ccivil_03/_ato20072010/2007/decreto/d6564.htm>. Acesso em: 30 jun. 2015.

Lei 8.742, de 7 de dezembro de 1993. Dispõe sobre a organização da Assistência Social e dá outras providências. Diário Oficial [da] República Federativa do Brasil. Brasília, DF, 8 dez. 1993. Disponível em: <http://www.planalto.gov.br/ccivil_ 03/lEIS/L8742.htm>. Acesso em: 30 jun. 2015.

Lei 9.533, de 10 de dezembro de 1997. Autoriza o Poder Executivo a conceder apoio financeiro aos Municípios que instituírem programas de garantia de renda mínima associados a ações socioeducativas. Diário Oficial [da] República Federativa do Brasil. Brasília, DF, 11 dez. 1997. Disponível em: <http://www.planalto.gov.br/ ccivil_03/Leis/L9533.htm>. Acesso em: 15 ago. 2012.

Lei 10.689, de 13 de junho de 2003. Cria o Programa Nacional de Acesso à Alimentação - PNAA. Diário Oficial [da] República Federativa do Brasil. Brasília, DF, 16 jun. 2003. Disponível em: <http://www.planalto.gov.br/ccivil_03/Leis/2003/L10.689.htm>. Acesso em: 15 jul. 2015.

Lei 12.435 , de 6 de julho de 2011. Altera a Lei $n^{\circ} .8 .742$, de 7 de dezembro de 
1993, que dispõe sobre a organização da Assistência Social. Diário Oficial [da] República

Federativa do Brasil. Brasília, DF, 07 jul. 2015. Disponível em: <http://www.planalto.gov.br/ccivil_03/_ato2011-2014/2011/Lei/L12435.htm>. Acesso em: 30 jun. 2015.

. Lei 12.470, de 31 de agosto de 2011. Altera os arts. 21 e 24 da Lei $n^{\circ} 8.212$, de 24 de julho de 1991, que dispõe sobre o Plano de Custeio da Previdência Social, para estabelecer alíquota diferenciada de contribuição para o microempreendedor individual e do segurado facultativo sem renda própria que se dedique exclusivamente ao trabalho doméstico no âmbito de sua residência, desde que pertencente a família de baixa renda; altera os arts. 16, 72 e 77 da Lei $\mathrm{n}^{\circ}$. 8.213, de 24 de julho de 1991, que dispõe sobre o Plano de Benefícios da Previdência Social, para incluir o filho ou o irmão que tenha deficiência intelectual ou mental como dependente e determinar o pagamento do salário-maternidade devido à empregada do microempreendedor individual diretamente pela Previdência Social; altera os arts. 20 e 21 e acrescenta o art. 21-A à Lei no 8.742, de 7 de dezembro de 1993 - Lei Orgânica de Assistência Social, para alterar regras do benefício de prestação continuada da pessoa com deficiência; e acrescenta os $\S \S 4$ o e 5o ao art. 968 da Lei $n^{\circ} .10 .406$, de 10 de janeiro de 2002 - Código Civil, para estabelecer trâmite especial e simplificado para o processo de abertura, registro, alteração e baixa do microempreendedor individual. Diário Oficial [da] República Federativa do Brasil. Brasília, DF, 01 set. 2011. Disponível em: <http://www.planalto.gov.br/ccivil_03/_ato2011-2014/2011/Lei/L12470.htm> Acesso em: 30 jun. 2015.

Lei 13.146, de 6 de julho de 2015. Institui a Lei Brasileira de Inclusão da Pessoa com Deficiência (Estatuto da Pessoa com Deficiência). Diário Oficial [da] República Federativa do Brasil. Brasília, DF, 07 jul. 2015. Disponível em: <http:// http://www.planalto.gov.br/ccivil_03/_Ato2015-2018/2015/Lei/L13146.htm>. Acesso em: 30 jul. 2015.

BRASIL. Fórum Nacional dos Juizados Especiais Federais. Enunciado 51: O artigo 20, parágrafo primeiro da Lei 8.742-93 não é exauriente para delimitar o conceito de unidade familiar. Disponível em: <http://www.trf4.jus.br>. Acesso em 15 jul. 2015.

BRASIL. Superior Tribunal de Justiça. Agravo Regimental no Recurso Especial $\mathrm{n}^{\circ}$. 529.928/SP. Agravante: INSS. Agravado: Orlando Jacinto (representado). Relator: Ministro Arnaldo Esteves Lima. DJ 3/04/2006. Disponível em <http://www.stj.jus.br>. Acesso em: 13 jul. 2015.

Agravo Regimental no Recurso Especial nº 1.177.395/PR. Agravante: INSS. Agravado: Adriana Ferreira da Silva. Relator: Ministro Jorge Mussi. DJ 24/05/2010. Disponível em: 〈http:// www.stj.jus.br>. Acesso em: 12 jul. 2015.

BRASIL. Supremo Tribunal Federal. ADI no. 1.232 - DF. Requerente: Procurador-Geral da República. Requerido: Presidente da República; Congresso Nacional. Relator: Ministro Sepúlveda Pertence. Redator do acórdão: Ministro Nelson Jobim. DJ 01/06/2001. Disponível em: 〈http://www.stf.jus.br>. Acesso em: 02 jul. 2015.

Agravo Regimental no Agravo de Instrumento no 470.975-6/SP. Agravante: INSS. Agravado: Diamantina Golçalves dos Santos. Relatora: Ministra Cármen Lúcia. DJ 18/12/2006. Disponível em: <http://www.stf.jus.br>. Acesso em 23 jul. 2015. 
Medida Cautelar na Reclamação no. 4.374-PE. Reclamante: INSS. Reclamado: Turma Recursal dos Juizados Especiais Federais do Estado de Pernambuco. Relator: Ministro Gilmar Mendes. DJ 06/02/2007. 1o fev. 2007. Disponível em: <http://www.stf.jus.br>. Acesso em 23 jul. 2015.

. Reclamação no. 4.374-PE. Reclamante: INSS. Reclamado: Turma Recursal dos Juizados Especiais Federais do Estado de Pernambuco. Relator: Ministro Gilmar Mendes. DJ 04/09/2013. Disponível em: < http://www.stf.jus.br>. Acesso em 13 jul. 2015.

BRASIL. Tribunal Regional Federal da $4^{\text {a }}$ Região. Turma Nacional de Uniformização dos Juizados Especiais. Súmula 48: A incapacidade não precisa ser permanente para fins de concessão do benefício assistencial de prestação continuada. Disponível em: < https://www2.jf.jus.br/phpdoc/virtus/sumula.php?nsul=48 >. Acesso em: 13 jul. de 2015.

Turma Regional de Uniformização do Tribunal Regional Federal da $4^{\mathrm{a}}$ Região (TRU): Súmula 6: O critério de verificação objetiva da miserabilidade correspondente a $1 / 4$ (um quarto) do salário mínimo, previsto no art. 20, § $3^{\circ}$, da Lei $\mathrm{n}^{\circ} 8.742 / 93$, restou modificado para $1 \frac{1}{2}$ (meio) salário mínimo, a teor do disposto no art. $5^{\circ}$, I, da Lei $\mathrm{n}^{\circ} 9.533 / 97$, que autorizava o Poder Executivo a conceder apoio financeiro aos Municípios que instituíssem programas de garantia de renda mínima associados a ações socioeducativas, e art. $2^{\circ}$, $2^{\circ}$, da Lei $n^{\circ}$ 10.689/2003, que instituiu o Programa Nacional de Acesso à Alimentação - PNAA. (Cancelada em: 07/07/2006). Disponível em: 〈http://www.trf4.jus.br>. Acesso em 15 jul.

2015.

FOLLMAN, Melissa. O Benefício de Assistência Social Previsto na CF/88, Art. 203, à Luz do Direito e da Sociedade, pp. 365-385. In: ROCHA, Daniel Machado da; SAVARIS, José Antônio (Coords.). Curso de especialização em direito previdenciário. Curitiba: Juruá, 2006.

IBRAHIM, Fábio Zambitte. Curso de direito previdenciário. 16 ed. Niterói: Impetus, 2011.

MORO, Sérgio Fernando. Os pobres, os pobres idosos e os pobres deficientes. Revista de Previdência Social. Ano XXVI, n. 261. São Paulo: Ltr, 2002.

Questões controvertidas sobre o benefício da assistência social, pp.143-160. In: ROCHA, Daniel Machado da (Coord.). Temas atuais de direito previdenciário e assistência social. Porto Alegre: Livraria do Advogado, 2003.

MUNIZ, Egli. A assistência social brasileira e portuguesa: um estudo comparativo. Disponível em: <http://bdjur.stj.jus.br/xmlui/bitstream/handle/2011/18432/A_Assist\%C3\% AAncia_Social_Brasileira_e_Portuguesa.pdf?sequence=2>. Acesso em: 07 jul. 2015.

SANTOS, Bruno Henrique Silva. Algumas considerações acerca do benefício assistencial de prestação continuada. Revista de Doutrina do TRF da 4a Região. n. 05. Disponível em: <http://www.revistadoutrina.trf4.jus.br>. Acesso em: 05 ago. 2015.

SAVARIS, José Antonio. Assistência social e a inclusão excludente da pessoa com deficiência. Justiça Federal em Revista. Curitiba. Ano XXI, n. 112, p. 11, janeiro/2009. 
SEN, Amartya. Desenvolvimento como liberdade. São Paulo: Companhia das Letras, 2000.

WICKERT, Magali. Assistência Social: benefícios e previsão constitucional. Revista de Doutrina do TRF da 4a Região. n. 25. Disponível em: <http://www.trf4.jus.br/ trf4/upload/editor/hll_DocumentaPeriodicos352008.pdf>. Acesso em: 07 jul. 2015. 